\title{
GCU
}

Glasgow Caledonian

University

University for the Common Good

\section{Surface finish control by electrochemical polishing in stainless steel 316 pipes}

Gomez-Gallegos, A.A.; Mill, F.; Mount, A.R.

Published in:

Journal of Manufacturing Processes

DOI:

10.1016/j.jmapro.2016.05.010

Publication date:

2016

Document Version

Author accepted manuscript

Link to publication in ResearchOnline

Citation for published version (Harvard):

Gomez-Gallegos, AA, Mill, F \& Mount, AR 2016, 'Surface finish control by electrochemical polishing in stainless steel 316 pipes', Journal of Manufacturing Processes, vol. 23, pp. 83-89.

https://doi.org/10.1016/j.jmapro.2016.05.010

\section{General rights}

Copyright and moral rights for the publications made accessible in the public portal are retained by the authors and/or other copyright owners and it is a condition of accessing publications that users recognise and abide by the legal requirements associated with these rights.

Take down policy

If you believe that this document breaches copyright please view our takedown policy at https://edshare.gcu.ac.uk/id/eprint/5179 for details of how to contact us. 


\title{
Surface finish control by Electrochemical Machining in Stainless steel pipes
}

\author{
A Gomez-Gallegosa,*, F Milla, A R Mountb \\ a School of Engineering, The University of Edinburgh, Edinburgh, EH9 3JL, United Kingdom \\ b School of Chemistry, The University of Edinburgh, Edinburgh, EH9 3JJ, United Kingdom \\ *Corresponding author, a.gomez@ed.ac.uk
}

\begin{abstract}
Electrochemical machining (ECM) is a non-conventional machining process based on the localized anodic dissolution of any conductive material. One of the main applications of ECM is to shape materials with enhanced characteristics, such as high strength, heat-resistance or corrosion-resistance. For the present work, ECM was applied in samples of Stainless Steel 316 (SS316), which is characterised by its high corrosion resistance, and pharmaceutical and medical applications [1]. The interest of studying ECM on stainless steels (SS) resides on the fact that a repeatable surface finish is not easily achieved. The present work presents a revision of the parameters involved in the ECM of SS with the objective of predicting the resulting surface finish on the sample. To achieve this, a series of ECM experimental tests on SS316 pipes of $1.5^{\prime \prime}(0.0381 \mathrm{~m})$ diameter were conducted varying machining parameters such as voltage, interelectrode gap, and electrolyte inlet temperature and electrolyte flow rate. The surface finish of the samples was then evaluated in order to find the significance of each of these parameters on the surface quality of the end product.
\end{abstract}

Results showed that overvoltage, which is dependent on the interelectrode gap and the electrolyte temperature, was one of the main parameters affecting the surface finish; additionally there is a strong relationship between the resulting surface finish and the electrolyte flow. The interelectrode gap and inlet electrolyte temperature also affect the resulting surface finish but their influence was not so evident. Finally, the variation of the electrolyte temperature during the process was found to have a great impact on the uniformity of the surface finish along the sample. We believe that this contribution should allow tailoring the surface finish to specific applications and reducing manufacturing costs and duration of the ECM process.

Keywords: Electrochemical Machining, stainless steel 316, surface finish.

\section{Introduction}

ECM of metals with special characteristics, such as enhanced strength, heat or corrosion resistance, is a manufacturing option to produce products that could be difficult or impossible to get with conventional manufacturing processes. ECM allows manufacturers to shape any conductive material without affecting the properties of the tool or the workpiece, while ensuring a high quality surface finish at the workpiece. 
ECM consists of an electric circuit formed by the tool and the workpiece connected to an external electrical source. The electrodes are submerged in an electrolyte bath that closes the circuit. When current passes through the circuit, a localised anodic dissolution occurs at the workpiece that results in more or less the negative shape of the tool profile [2]. The electrolyte is pumped through the interelectrode gap dragging the dissolved material and cooling down the electrodes. Unfortunately, the ECM process is difficult to predict due to the wide variety of physical phenomena involved and the lack of enough quantitative and qualitative data that could be used in the development of an accurate simulation model $[3,4]$.

Additionally, ECM is not a process that regularly generates repeatable results, e.g. the application of ECM on stainless steels (SS) typically generates various different surface finish. Some studies [5-9] had been done in order to understand the behaviour of the ECM of SS, however the process is not fully understood yet. SS are iron chromium alloys, typically with greater than 10 weight percentage (wt $\%$ ) chromium, that gives them the special characteristic to being corrosion resistant. The chromium induces the formation of a protective oxide film on the metal surface that prevents further corrosion [9]. This oxide film has low electrical conductivity and prevents the workpiece from a direct contact with the electrolyte, so normal anodic dissolution cannot proceed without breakdown of the film. Partial breakdown of the oxide film often occurs, which causes pitting on the surface [10] or a non-uniform surface finish [5].

An electrochemically polished surface is usually associated with the random removal of atoms from the anode (workpiece), whose surface has become covered with the oxide film. The effective removal of this film and the workpiece material is governed by a combination of metal-electrolyte-machining parameters. Hence, for the present work, the ECM machining parameters, gap, voltage, flow rate and inlet electrolyte temperature, were modified in order to evaluate their role on the achievement of the expected surface finish and a homogeneous breakdown of the oxide film.

\section{Experimental method}

\section{Sample preparation}

The pipes machined were commercial stainless steel 316 (SS316) pipes of $0.17 \mathrm{~m}$ length and $0.0381 \mathrm{~m}$ diameter, which were manufactured by rolling and welding. The pipe material, prior to processing, was dark and opaque and the surface finish quality was uniform along the pipe. Welding left behind a weldflash at the interior face of the pipe. The exterior of the pipe was not treated. 


\section{Electrochemical (ECM) setup}

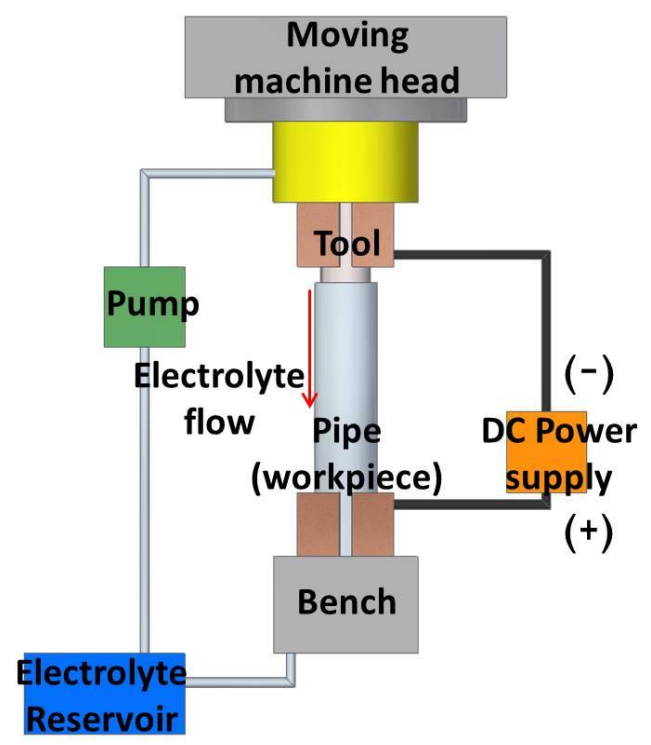

Figure 1. Schematic of the electrochemical machining system.

Figure 1 shows the ECM array consisting of a cylindrical solid tool and a pipe (workpiece) placed vertically and concentric to each other on the bedplate of the ECM machine. The tool was held by the machine head and the workpiece was fixed to the bedplate by a non-conductive clamp. The electrolyte flowed from top and between the pipe and the tool, and the setup was positioned in a fashion allowing the electrolyte to exit the array.

\section{Test parameters}

The tool had the same dimensions as the pipe, and its diameter was the one of the interior diameter of the pipe (workpiece) but undersized radially by 2,4 or $8 \mathrm{~mm}$. Electrical clips were connected to the toolworkpiece array providing DC current under a constant voltage of 18, 24 and 36 Volts (possible voltage losses in the system were not considered). The electrolyte used was Sodium Nitrate $\left(\mathrm{NaNO}_{3}\right)$ with specific gravity (S.G.) of 1.15. Figure 2 shows the density and the conductivity of the electrolyte as a function of the temperature. Electrolyte flow rate was recirculated and set at 10, 25, 40 and $60 \mathrm{~L} / \mathrm{min}$. The inlet electrolyte temperature was considered constant; however the machining was developed in two different days, so the room temperature changed from 7 to $15.3^{\circ} \mathrm{C}$. The current during the process was measured and recorded using the accompanying data acquisition software, provided by pEMC systems Ltd (R). Each test lasted for 10 seconds. 

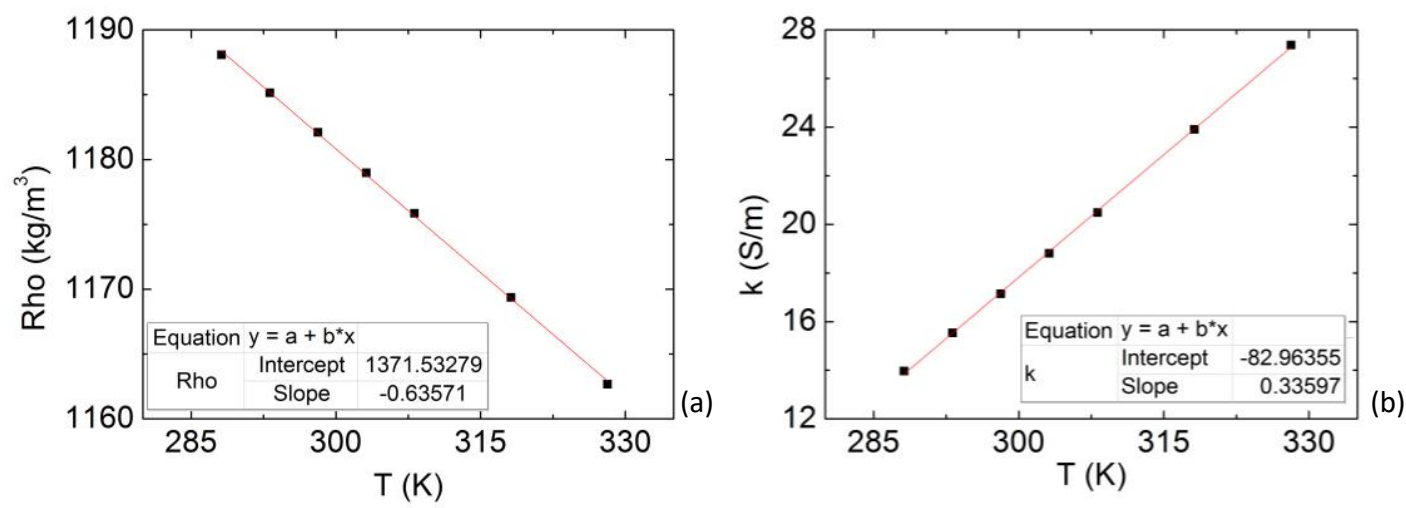

Figure 2. Density (a) and conductivity (b) of $\mathrm{NaNO}_{3}$ in relation with the temperature [11] at 22\% mass percent. Fitting line (red line) and equation describing the density and behaviour are presented.

\section{Results and discussion}

The chromium in SS induces the formation of a protective film of oxide on the material surface [9]. This film needs to be broken by the ECM process in order to dissolve the material. A partial breakdown of this film is a common problem during ECM and results in non-uniform surface finish of the workpiece $[5,8,10]$. Additionally, the surface finish of the samples results from the specular or non-specular reflection of light from the crystal faces electrochemically dissolved at different rates during the ECM process [2].

Table 1 summarises the resulting surface finish qualities of the samples after the ECM. The samples were divided in four categories according its surface finish quality: passivated at the entrance and reflective at the exit, reflective and bright, reflective and dark, and passivated.

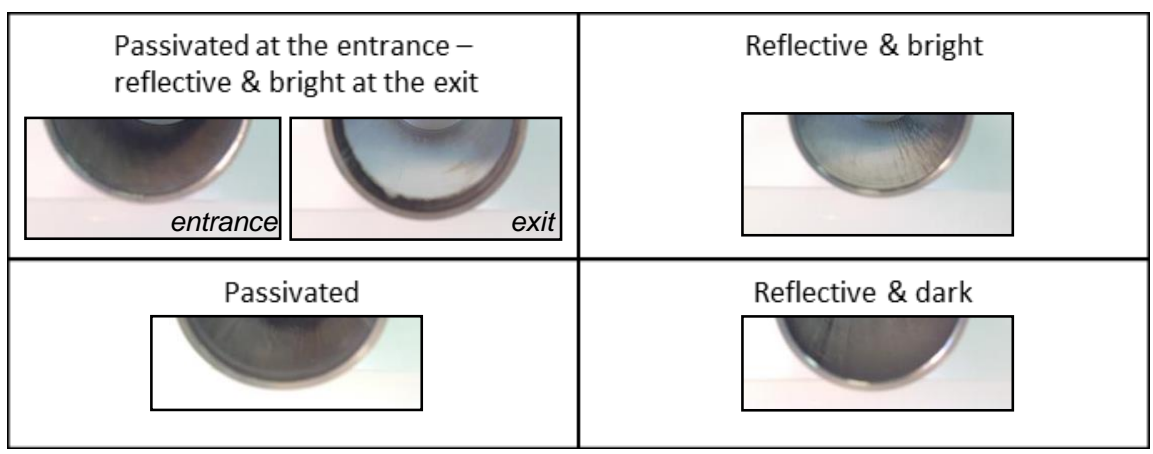

Table 1. Surface finish classification of the SS316 pipes machined by ECM.

The ECM parameters, such as current density $(J)$, overpotential $\left(V_{0}\right)$ and temperature difference $(\delta T)$, which are dependent on the controlled parameters (voltage, gap, electrolyte inlet temperature and flow rate), were compared with the objective of finding which of them had an influence, if any, on the resulting 
surface finish of the sample. By properly adjusting the process parameters, we expect to achieve a reflective and bright surface finish.

\section{Overpotential $\left(V_{0}\right)$}

Metal dissolution was accomplished by the deliberated application of an external potential difference between the electrodes during the ECM process. The potential needed to ensure a continuous discharge of metal between the electrode and the electrolyte is named overpotential $\left(V_{0}\right)$. The results of the present work show the importance of $V_{0}$ in the resulting surface finish at the SS316 samples. Previous works $[5,8]$ found that a bright and reflective surface finish is achieved when $V_{0}$ is in the range of 9.7 and $12.4 \mathrm{~V}$. From our results, this range is wider, $9.1-15.0$ V. See Figure 3.

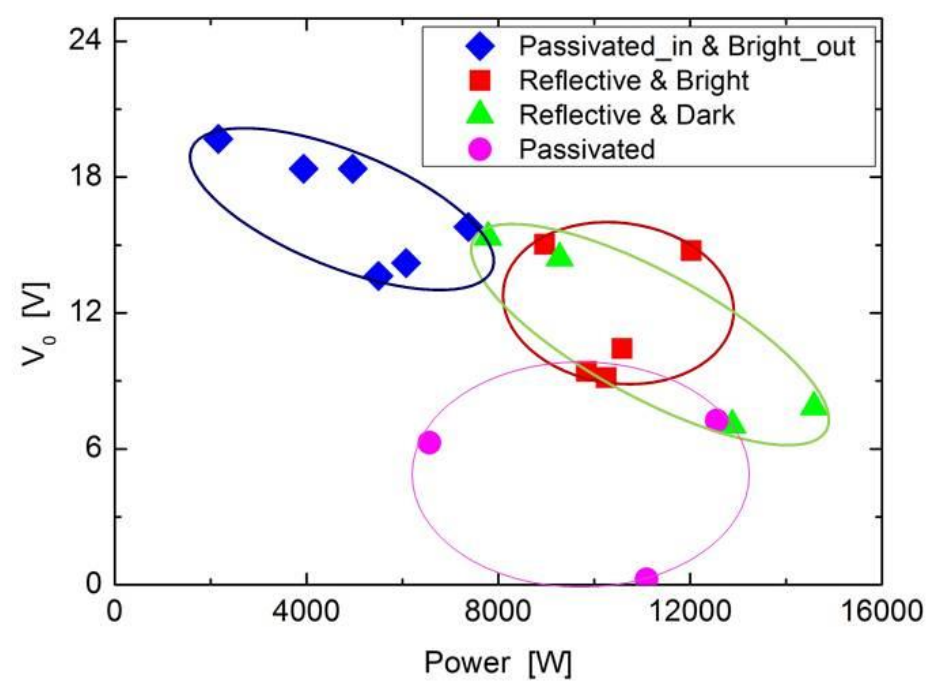

Figure 3. Power, $P$, and overpotential, $V_{0}$, in relation with the surface finish: passivated entrance reflective and bright exit (rhomboids), reflective and bright (squares), reflective and dark (triangles), and passivated (circles).

Figure 3 shows the relationship between the power (function of the voltage and current applied) and the overpotential during the ECM process. Samples that present a more uniform reflective surface finish (squares and the triangles in Figure 3) are observed when the power is over $7 \mathrm{KW}$ and the overpotential is limited between the 7 and $15 \mathrm{~V}$. In the samples where the surface finish is not uniform along them (rhomboids), i.e. a passivated surface was found at the entrance and a reflective and bright surface at the exit; the overpotential is over $14 \mathrm{~V}$ and the power is below $7 \mathrm{KW}$. A plausible explanation for this behaviour is that the potential difference is not enough for maintaining a steady ion migration though the oxide film, hence a non-uniform surface finish is attained. This is consistent with previous work [A.R. Mount,2003] where these areas of different surface finish were related with a variation in the valence ( $z$ ) of SS316. Mount et al. [5] in their studies of ECM in SS found that at $z=3.5 \pm 0,1$, the resulting surface finish in the SS workpiece was reflective and bright, however, if $z$ was lower, $2.5 \pm 0.1$, the surface was 
passivated. This surface finish is also characteristic of iron and chromium dissolving in their high valence states (as $\mathrm{Fe}(\mathrm{III}), z_{F e}=3$, and $\mathrm{Cr}(\mathrm{VI}), z_{C r}=9$ ) [5]. In our work, however we didn't measure the valence during the ECM process, so these findings could not being verified. Additionally, when the overpotential is below $7 \mathrm{~V}$, the surface finish is passivated (circles in Figure 3). In these cases the potential drop between the electrodes is too high, so even though the oxide film is broken, the dissolution of the metal is uncontrolled [12].

\section{Current density $(J)$}

McGeough in 2005 [2] noted that when the current density, $J$ was raised, the surface finish on the workpiece becomes smoother. Lozano-Morales in 2009 [10] found the same behaviour when applied ECM in Niobium samples. Figure 4 presents the influence of $J$ in the resulting surface finish. For $J$ over $4.5 \mathrm{~A} / \mathrm{cm}^{2}$ and $P$ over $7 \mathrm{~kW}$ (squares and the triangles in Figure 5) a reflective surface is achieved. However, when J or P dropped below those values, there was not enough energy to break uniformly the oxide film, hence a passivated or non-uniform surface finish was obtained. Moreover when V0 is too high and $J$ is not enough to maintain a stable migration of ions from the workpiece, a non-uniform surface finish is attained (rhomboids in Figure 4).

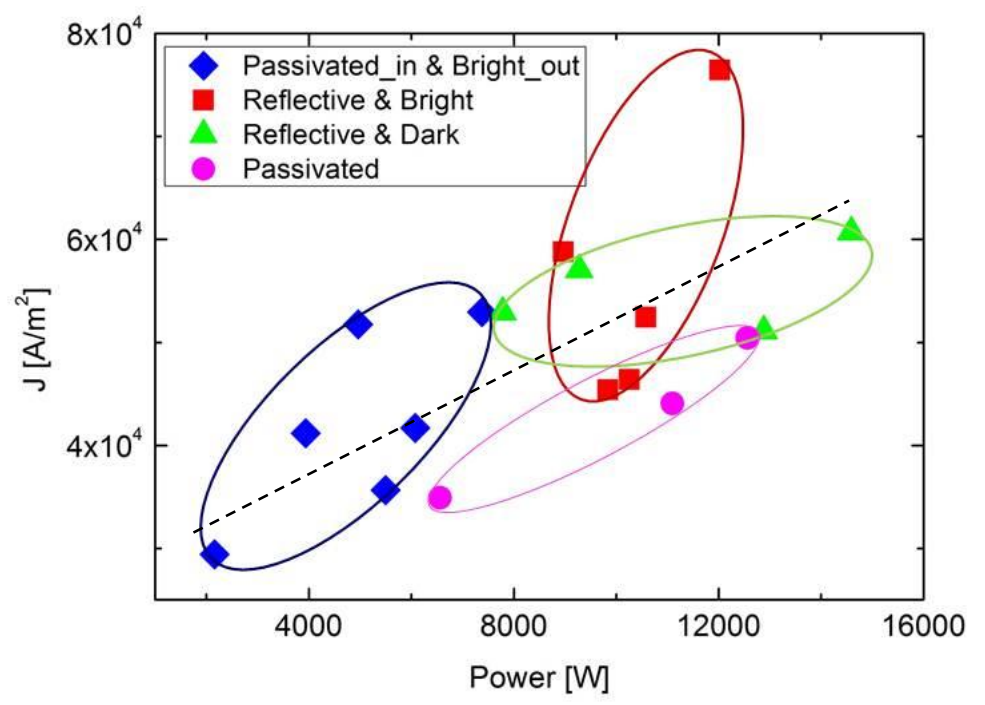

Figure 4 Current density, $J$, and Power, $P$, in relation with the surface finish: passivated entrance reflective and bright exit (blue rhomboids), reflective and bright (red squares), reflective and dark (green triangles), and passivated (pink circles).

\section{Flow rate}

The role of the electrolyte flow rate is twofold: it flushes away the metal ions (ECM products) dissolved from the anode before they can reach the cathode and, at the same time mitigates the temperature increase of the system. The accumulation of the machining products could lead to a shortcut of the 
system, and the increase of the temperature affects the conductivity of the electrolyte [2]. Hence, there is an impact of the flow rate in the overpotential during the process.

Figure 5 demonstrates the influence of the electrolyte flow rate on the surface finish. Low flow rates $(<20$ $\mathrm{L} / \mathrm{min}$ ) result in a passivated or a non-uniform surface finish along the sample, which is due to the heat generated during the ECM process was not well dissipated. Usually the change in temperature results in a change in the conductivity of the electrolyte, which is temperature dependent, thus affecting the resulting surface finish. McGeough [2] stated that the surface is smoother when the electrolyte velocity is increased, however if the flow rate is too high $(>40 \mathrm{~L} / \mathrm{min})$ the process results in a dark surface (triangles in Figure 5). From previous works [13] we know that this film is mainly formed by Fe, $\mathrm{C}$ and small traces of $\mathrm{Cr}$, and it is highly attached to the metal surface. Additionally, this oxide film limit the current efficiency [14] during the ECM process. Results show that the flow rate that generates a reflective and bright surface finish is approximately $25 \mathrm{~L} / \mathrm{min}$ (squares in Figure 5).

Wagner, T. (2002) gave a plausible explanation of the effect of the electrolyte flow rate on the surface finish on SS. During ECM, the electric current breaks the oxide film and local electrolyte flow turbulences would ideally remove the film particles (oxides, chromium carbides and reaction products). If the turbulence is not enough to remove these lose particles, $\mathrm{Fe}^{\mathrm{n}+}$ - diffusion through the surface layer is possible, and the current density efficiency decreases drastically, affecting the surface finish.

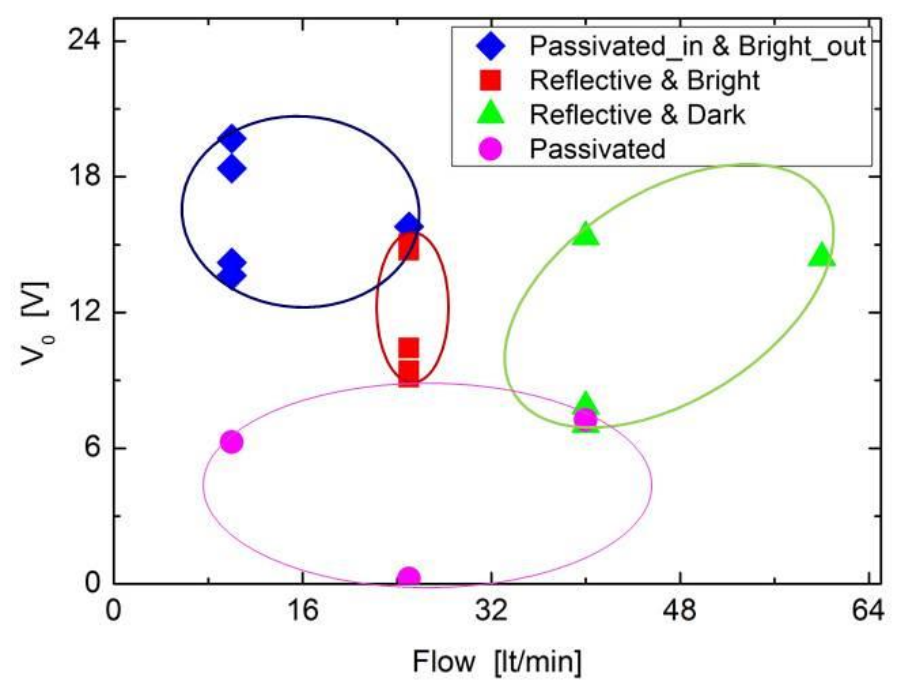

Figure 5. Electrolyte flow rate, $Q$, and overpotential, $V_{0}$, in relation with the surface finish: passivated entrance - reflective and bright exit (blue rhomboids), reflective and bright (red squares), reflective and dark (green triangles), and passivated (pink circles).

\section{Interelectrode gap}

The distance between the electrodes and in where the electrolyte flows is named interelectrode gap, and was demonstrated to be another important parameter determining the resulting surface finish of the 
sample. Figure 6 shows that a big gap $(\approx 8 \mathrm{~mm})$ generates a passivated surface finish. This is due the fact that the interelectrode gap is related inversely to the current density of the ECM process [15]; when $J$ is reduced, e.g. by increasing the gap, there is not enough energy during the process to break the oxide film uniformly [15].

Figure 5 shows the relationship between the surface finish, the electrolyte flow and the interelectrode gap. From fluid dynamics, it is known that the velocity of the flow increases when the interelectrode gap is smaller; when the electrolyte velocity is too low, the turbulence in the fluid is not enough for flushing away the ECM products.

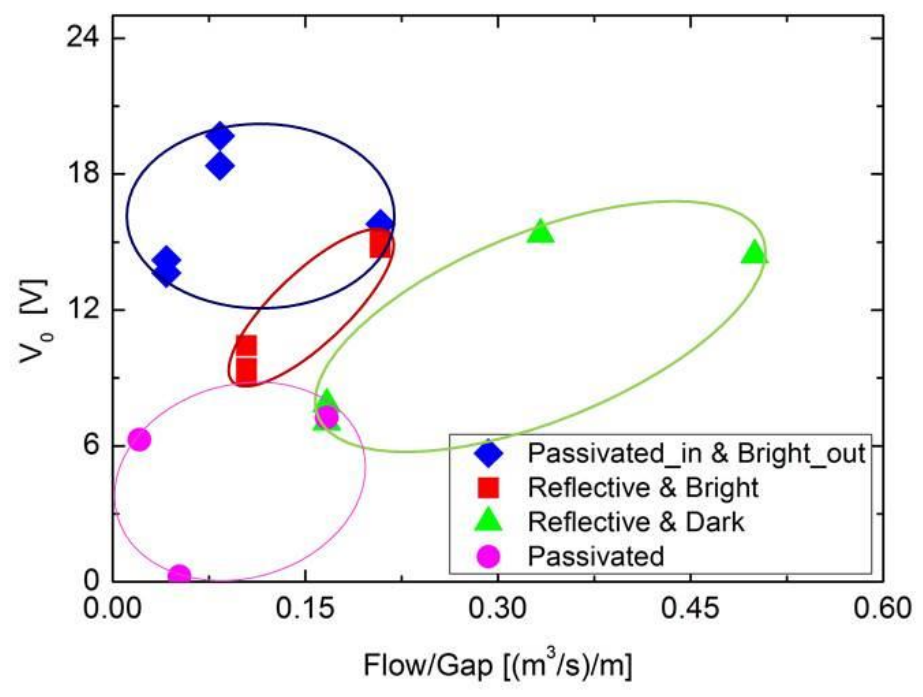

Figure 6. Electrolyte flow rate, $Q$, inter electrode gap, $y$, and overpotential, $V_{0}$, in relation with the surface finish: passivated entrance - reflective and bright exit (rhomboids), reflective and bright (squares), reflective and dark (triangles), and passivated (circles).

\section{Temperature difference $(\delta T)$}

Deconinck in 2010 [4] established how the electrochemical reactions rates depend strongly on the electrolyte temperature, which in turn depends on the electrolyte flow rate, interelectrode gap and potential applied. Moreover it is known that the electric conductivity is directly related with the temperature of the electrolyte $[16,17]$. When the conductivity changes, the electrochemical reactions during the ECM also change, thus affecting the resulting surface finish on the sample.

Some samples were found to have two different surface finish along their length following the flow path of the electrolyte. This non-uniform surface finish is usually characterised by a passivated section at the entrance and a reflective and bright one at the exit. We believe that that temperature of the electrolyte increases while flowing along the length of the sample due to Joule heating. When the temperature increases, the conditions of the ECM process change, resulting in a different surface finish. For a uniform 
surface finish, the temperature difference, $\delta T$, of the electrolyte across the length of the pipe, and in consequence its variation in conductivity, should be small $\left(<8^{\circ} \mathrm{C}\right)$.

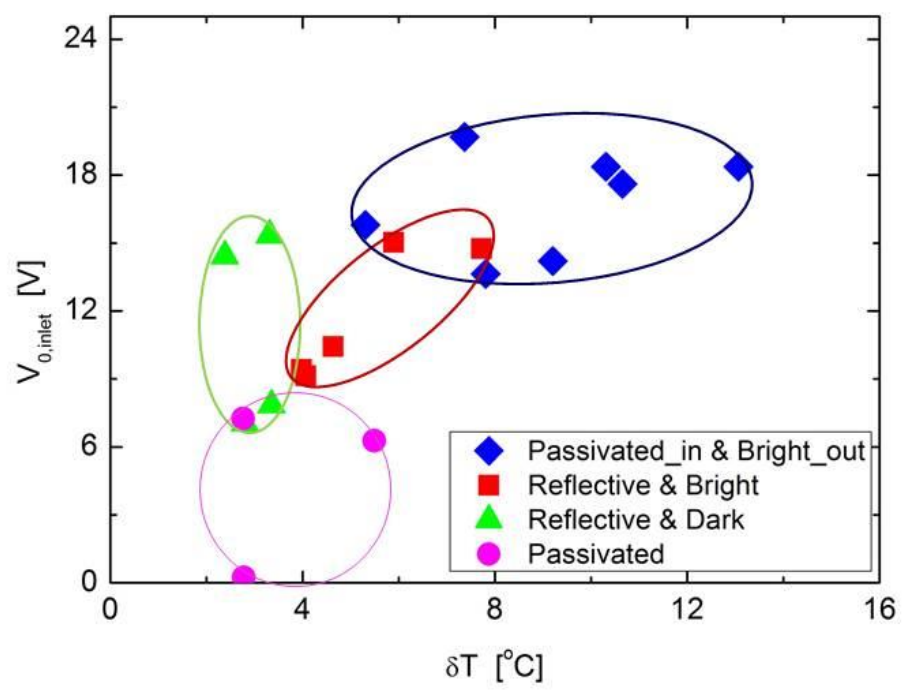

Figure 7. Temperature difference, $\delta T$, between the electrolyte inlet and outlet temperature, and overpotential, $V_{0}$, in relation with the surface finish: passivated entrance - reflective and bright exit (rhomboids), reflective and bright (squares), reflective and dark (triangles), and passivated (circles).

Figure 7 shows $\delta T$ along the length of the samples and their relationship with the resulting surface finish. The samples that present two different surface finish (rhomboids in Figure 7) are the ones whose $\delta T$ is high. This difference is usually result of an electrolyte flow rate that is not enough $(<25 \mathrm{~L} / \mathrm{min})$ to dissipate the heat of the ECM process. Additionally, it can be observed that a uniform surface finish is presented when $\delta T$ is low (squares, triangles and circles in Figure 7).

\section{Conclusions}

The present paper presents an experimental analysis of the parameters that influence the surface finish of SS316 samples machined with ECM. The machining parameters, voltage, gap, electrolyte flow rate, and electrolyte inlet temperature, were varied in turn, and the samples were divided according to the resulting surface finish.

Results highlight a strong relationship between surface finish and overpotential during ECM. The overpotential is dependent of the current density and the characteristics of the electrolyte. Thus the electrolyte flow rate, conductivity and inlet temperature directly affect the resulting surface finish. An overpotential between 9 and $15 \mathrm{~V}$ is necessary to obtain the desirable reflective and bright surface finish; if the overpotential was lower, a passivated surface usually was obtained. The variation in the electrolyte temperature during the process was found to have a great impact on the uniformity of the surface finish along the sample. A non-uniform surface finish along the length of some samples was characteristic of a 
low electrolyte flow rate, and hence deficient heat and ECM products dissipation. Additionally the interelectrode gap also affect the resulting surface finish but its influence was not so evident, however a big interelectrode gap, $8 \mathrm{~mm}$, usually results in a passivated surface finish. Current density (J) during the ECM process also demonstrated to have a big influence in the resulting surface finish; $J$ higher than 4.5 $\mathrm{A} / \mathrm{cm}^{2}$ is needed to obtain a reflective surface finish. However it's important to remember that $J$ is related with the interelectrode gap, and the temperature and conductivity of the electrolyte.

The results presented in this paper could be used as a tool for the achievement of the desired surface finish on a sample of SS316. We believe that this analysis and subsequent further development could be applied with other metal alloys and is an important step towards the understanding of the ECM process and an adequate prediction of the resulting surface finish. Moreover, the accurate determination of the fundamental relationships between the power, overpotential, interelectrode gap, current density and electrolyte flow rate and electrolyte temperature, will lead to more accurate computational simulations of the ECM process and aid the tool design techniques. However more experimental work is still needed.

\section{Acknowledgements}

The author would like to thank Steve Duffield from pECM systems Ltd. for the experimental samples and experience; and to The Mexican National Council for Science and Technology (CONACyT) for the support and provision of the scholarship to AAGG for the development of this project.

\section{References}

[1] ASM.matweb.com, AISI Type 316 Stainless Steel, annealed sheet, ASM Aerosp. Specif. Met. Inc. (2007). http://asm.matweb.com/search/SpecificMaterial.asp?bassnum=MQ316A.

[2] J.A. McGeough, Electrochemistry Encyclopedia: Electrochemical Machining (ECM), Http://electrochem.cwru.edu/encycl/. (2005). http://electrochem.cwru.edu/encycl/art-m03machining.htm.

[3] M.M. Lohrengel, I. Klüppel, C. Rosenkranz, H. Bettermann, J.W. Schultze, Microscopic investigations of electrochemical machining of $\mathrm{Fe}$ in NaNO3, Electrochim. Acta. 48 (2003) 3203 - 3211. doi:http://dx.doi.org/10.1016/S0013-4686(03)00372-4.

[4] D. Deconinck, S. Van Damme, C. Albu, L. Hotoiu, J. Deconinck, Study of the effects of heat removal on the copying accuracy of the electrochemical machining process, Electrochim. Acta. 56 (2011) 5642 - 5649. doi:10.1016/j.electacta.2011.04.021.

[5] A.R. Mount, D. Clifton, P.S. Howarth, A. Sherlock, An integrated strategy for materials characterisation and process simulation in electrochemical machining, J. Mater. Process. Technol. 138 (2003) 449-454. http://www.sciencedirect.com/science/article/B6TGJ-48KFK653/2/1775da859fa84cf26b560b42bfce7d06.

[6] E. Rosset, M. Datta, D. Landolt, Electrochemical dissolution of stainless steels in flow channel cells with and without photoresist masks, J. Appl. Electrochem. 20 (1990) 69-76. doi:10.1007/bf01012473. 
[7] J. Ramousse, J. Deseure, O. Lottin, S. Didierjean, D. Maillet, Modelling of heat, mass and charge transfer in a PEMFC single cell, J. Power Sources. 145 (2005) 416-427. doi:http://dx.doi.org/10.1016/j.jpowsour.2005.01.067.

[8] A.R. Mount, P.S. Howarth, D. Clifton, The use of a segmented tool for the analysis of electrochemical machining, J. Appl. Electrochem. 31 (2001) 1213-1220. http://dx.doi.org/10.1023/A:1012740704713.

[9] A.R. Mount, P.S. Howarth, D. Clifton, The Electrochemical Machining Characteristics of Stainless Steels, J. Electrochem. Soc. 150 (2003) D63-D69. doi:10.1149/1.1545463.

[10] A. Lozano-Morales, Niobium Electropolishing Using an HF-free Electrolyte, Plat. Surf. Finish. 96 (2009).

[11] T. Isono, Density, viscosity, and electrolytic conductivity of concentrated aqueous electrolyte solutions at several temperatures. Alkaline-earth chlorides, lanthanum chloride, sodium chloride, sodium nitrate, sodium bromide, potassium nitrate, potassium bromide, a, J. Chem. Eng. Data. 29 (1984) 45-52. doi:10.1021/je00035a016.

[12] J. Bannard, On the electrochemical machining of some titanium alloys in bromide electrolytes, J. Appl. Electrochem. Soc. 6 (1976) 477. http://dx.doi.org/10.1007/BF00614536.

[13] T. Haisch, E. Mittemeijer, J.W. Schultze, Electrochemical machining of the steel $100 \mathrm{Cr} 6$ in aqueous $\mathrm{NaCl}$ and NaNO3 solutions: microstructure of surface films formed by carbides, Electrochim. Acta. 47 (2001) 235 - 241. doi:http://dx.doi.org/10.1016/S0013-4686(01)00561-8.

[14] J.A. McGeough, Principles of electrochemical machining, Chapman and Hall, London, 1974.

[15] M. Hackert-Oschätzchen, S.F. Jahn, A. Schubert, Design of Electrochemical Machining Processes by Multiphysics Simulation, in: COMSOL (Ed.), COMSOL Conf. 2011, Stuttgart, 2011.

[16] D. Deconinck, S. Van Damme, J. Deconinck, S. Van Damme, A temperature dependent multi-ion model for time accurate numerical simulation of the electrochemical machining process. Part I: Theoretical basis, Electrochim. Acta. 60 (2012) 321 - 328. doi:10.1016/j.electacta.2011.11.070.

[17] J. Kozak, K.P. Rajurkar, R. Balkrishna, Study of Electrochemical Jet Machining process, J. Manuf. Sci. Eng. Asme. 118 (1996) 490-498. <Go to ISI>://A1996VV33400004. 